\title{
The Biogeochemistry of Pu and U: Distribution of Radionuclides Affected by Micro-Organisms and Their Siderophores, Reductants, and Exopolymers
}

Traina, Samuel J.

Ohio State University

\begin{abstract}
RESULTS TO DATE: Investigations to date focused on studying the dissolution of oxides and desorption of metals by the siderophore, Desferrioxamine B (DFB), with different metal ions adsorbed onto the solids. X-ray absorption spectroscopy (XAS) was used to probe the surface structural environment of sorbed metal ions. Results indicated that while DFB effectively dissolved iron oxides with different adsorbed metals, this process was also affected by the type of the metal adsorbed. For pure hematite, samples with adsorbed metals had less dissolved Fe by DFB than the one without. Different type of metal ion seemed to have no significant effects on Fe dissolution under these experimental conditions. This result suggested that while adsorbed metals blocked available surface sites on hematite surfaces for DFB causing less Fe release, Fe dissolution by DFB from the well crystalline structure of hematite was not affected by the adsorbed metal ions.
\end{abstract}

DELIVERABLES: The Biogeochemistry of Pu and U: Distribution of Radionuclides Affected by Microorganisms and their Siderophores, Reductants, and Exopolymers

Larry Hersman, Jennifer Forsythe, Joseph Lack, Christy Ruggiero, Mary Neu, and Samuel Traina Annual NABIR Conference 